\title{
Effect of Thermal Stimulation on Various Characteristics of Superplasticizer
}

\author{
Mizuki Takigawa, Yu Bomura, Shin-ichiro Hashimoto, and Shigeyuki Date
}

\begin{abstract}
It is widely known that basic performance of superplasticizer can be fluctuated by change of ambient temperature. However, it is not known that fluidity of concrete can be improved by thermal stimulation to superplasticizer. It was confirmed that fluidity of the mortar has been improved by heating superplasticizer in the previous study, therefore in this study, Examination of thermal stimulation effect on the molecular weight distribution of superplasticizer, the study of retention effect of fluidity after thermal stimulation of superplasticizer, and its sustainability were examined. As a result, it was confirmed that thermal stimulation doesn't negatively affect the molecular weight distribution and affects only the three-dimensional structure of the polymer molecule. Moreover, it was confirmed that the thermal stimulation effect not only sustained the improvement of the initial dispersion performance well but also did not lower the slump keeping performance thereafter. In addition to it was confirmed that the thermal stimulation effect lasted for about 7 days, and the residual characteristics differed depending on the superplasticizer.
\end{abstract}

Index Terms-Thermal stimulation, superplasticizer, slump life, flowability, molecular weight distribution.

\section{INTRODUCTION}

The superplasticizer is fulfilled the requirement as the same time of construction quality, durability, slump life, and adequate construction performance, it is most vast using as to new construction's materials. The performance of superplasticizer can be affected by difference from ingredients and intended using, dosage, type of cements, temperature, mix proportions and so on [1], [2].

Generally, it is widely known that the superplasticizers change the flowability of concrete by the ambient temperature [3]-[6]. However, it is not generally known that fluidity of concrete can be improved by heating superplasticizers. Moreover, previous study by Zabihollah et al. [7] clearly indicated that the fluidity can be improved with applicating of thermal stimulation to superplasticizers on ordinary portland cement. In addition, the paper by Takigawa et al. [8], [9] clearly indicated that three-dimensional structure of polymer in the superplasticizers will be changed by thermal stimulation. Other researchers [10]-[14] have reported that polycarboxylic acid-based and etheric polycarboxylic acids are relevant to Hydrophobic backbone, type of hydrophobic

Manuscript received November 5, 2018; revised May 2, 2019.

Mizuki Takigawa is with the Graduate School of Eng., Tokai University, Hiratsuka, Kanagawa, Japan (e-mail: 25concrete.4miz9@gmail.com).

Yu Bomura and Shigeyuki Date are with Tokai University, Hiratsuka, Kanagawa, Japan (e-mail: yu.bomura.tokai@gmail.com, sdat@tokai-u.jp).

Shin-ichiro Hashimoto is with Chiba Institute of Technology, Narashino, Chiba, Japan (e-mail: shinichiro.hashimoto@p.chibakoudai.jp). grafts, length, arrangement and functional group [3], [4]. More it has reported that the dispersion efficiency of cement increases in step with the number and length of hydrophobic grafts, and polymer molecular of hydrophobic grafts adsorb onto the surface of cement particles. Hydrophobic grafts of polymer were adsorbed to cement particle can have blocked them as against other cement particle and it has been reported that the fluidity of cement paste can be efforted by disable aggregation [15], [16]. These studies are the thermal stimulation effect in superplasticizer exert influence to increase the length of hydrophobic graft, and as the result of hypothesis have the potential for causing steric hindrance. Therefore, it is assumed that it can be possible to improve both productivity and quality of concrete work by heating superplasticizers and using it at the actual construction site. Although it was confirmed the fluidity improvement, little is known about keeping of fluidity. On the other hand, there is no validation on the change in molecular weight distribution due to thermal stimulations effect.

In this study, in order to confirm stability of the thermal stimulation effect for the practical use, a molecular weight of both stimulated sample and the control sample are measured, Based on this result, an effect of thermal stimulation on change of molecular structure. Moreover, it was confirmed that the sustainability of the performance change after the thermal stimulation to superplasticizer, the relation between the fluidity of mortar and slump life was evaluated to confirm sustainability of the effect of thermal stimulation to the performance of superplasticizer. In addition, after thermal stimulation to the superplasticizer, cooled slowly it and used it to knead the mortar and confirm the sustainability of thermal stimulation effect of the superplasticizer.
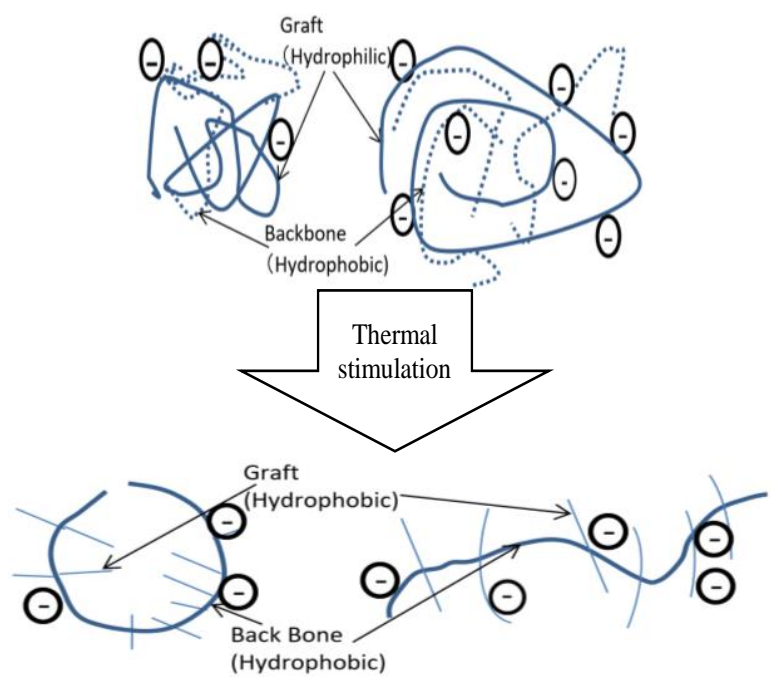

Fig. 1. The image of polymer structures changing by thermal stimulation. 
TABLE I: MATERIALS USED

\begin{tabular}{ccc}
\hline \multicolumn{1}{c}{ Materials } & Properties \\
\hline \hline Cement & $\mathrm{N}$ & $\begin{array}{c}\text { Ordinally Portland cement } \\
\text { Density: } 3.16 \mathrm{~g} / \mathrm{cm}^{3}\end{array}$ \\
\hline $\begin{array}{c}\text { Fine } \\
\text { Aggregate }\end{array}$ & $\mathrm{S}$ & $\begin{array}{c}\text { River sand from Kanagawa } \\
\text { Density: } 2.69 \% \\
\text { Water absorptivity: } 1.49 \%\end{array}$ \\
& $\mathrm{PCa}$ & $\begin{array}{c}\text { High range } \\
\text { water reducing agent }\end{array}$ \\
\cline { 2 - 3 } $\begin{array}{c}\text { Super } \\
\text { plasticizer }\end{array}$ & $\mathrm{RMC}$ & $\begin{array}{c}\text { High range } \\
\end{array}$ \\
\cline { 2 - 3 } & $\mathrm{DP}$ & $\begin{array}{c}\text { High dispersion type } \\
\text { high range }\end{array}$ \\
& & water reducing agent \\
\cline { 2 - 3 } & $\mathrm{SK}$ & $\begin{array}{c}\text { Slump keeping type } \\
\text { high range } \\
\text { water reducing agent }\end{array}$ \\
& &
\end{tabular}

TABLE II: CONDITIONS OF EXPERIMENT

\begin{tabular}{|c|c|c|c|c|c|c|}
\hline Cond. & $\begin{array}{c}\text { Type of } \\
\text { Ad }\end{array}$ & $\begin{array}{l}\text { W/C } \\
(\%)\end{array}$ & $\mathrm{S} / \mathrm{C}$ & $\begin{array}{c}\mathrm{Ad} / \mathrm{C} \\
(\%)\end{array}$ & $\begin{array}{l}\text { Heat } \\
\text { temp. } \\
\left({ }^{\circ} \mathrm{C}\right)\end{array}$ & $\begin{array}{c}\text { Heat } \\
\text { time } \\
(\mathrm{hr}) \\
\end{array}$ \\
\hline \multirow{4}{*}{ Case 1} & $\mathrm{PCa}$ & \multirow{6}{*}{30} & \multirow{6}{*}{2.0} & 0.56 & \multirow{6}{*}{60} & \multirow{6}{*}{24} \\
\hline & RMC & & & 0.84 & & \\
\hline & DP & & & 0.40 & & \\
\hline & SK & & & 5.30 & & \\
\hline \multirow{2}{*}{ Case 2} & $\mathrm{PCa}$ & & & 0.84 & & \\
\hline & RMC & & & 1.30 & & \\
\hline
\end{tabular}

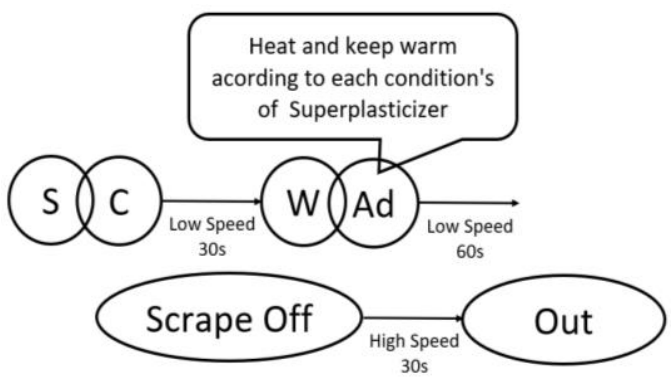

Fig. 2. Mixing procedure.

\section{EXPERIMENTAL PROCEDURE}

\section{A. Outline of Thermal Stimulation}

In this study, heating superplasticizers itself is hereinafter as referred to as "thermal stimulation". Fig.1 shows the image of polymer structures changing by thermal stimulation [8]-[10],[17]-[19]. Hypothesis about thermal stimulation that increase dispersion performance of cement because of increased adsorbed sites with cement hence superplasticizer was given to thermal stimulation. Especially make a conjecture that the more contained amount of slump keeping polymer can be improve the fluidity, because of short hydrophobic-graft was having compared slump keeping polymer with dispersion polymer [20].

\section{B. Material Used and Mixing Conditions of Mortal}

Materials used and conditions of experiment are shown in Table I and Table II kinds of superplasticizer as high range water reducing agent mainly used for precast concrete (hereinafter referred to as "PCa type") and high range water reducing agent $\mathrm{AE}$ type mainly used for ready mixed concrete (hereinafter referred to as "RMC type") were used for this study.

Moreover, 2 kinds of superplasticizer as high range water reducing agent with high dispersion type (hereinafter referred to as "DP type") and high range water reducing agent with high slump keeping type (hereinafter referred to as "SK type") were also used. An influence of type and content of slump keeping polymer on the effect of thermal stimulation were investigated.

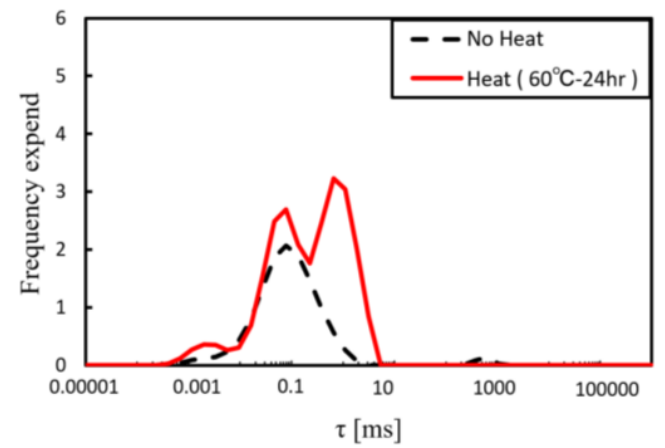

Fig. 3. Changing the molecular size (PCa type) [8].

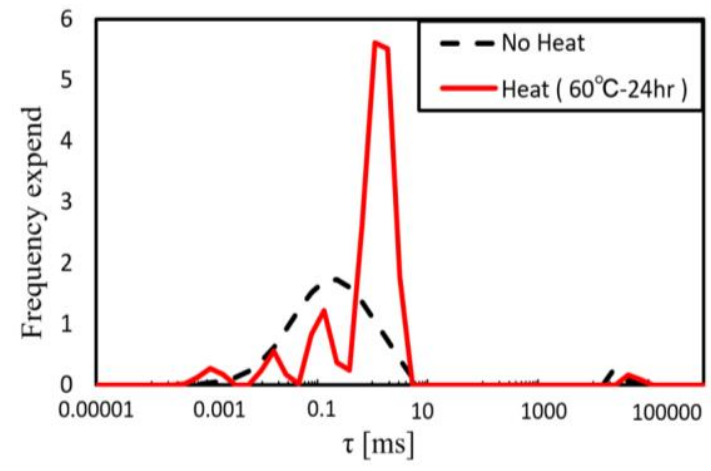

Fig. 4. Changing the molecular size (RMC type) [8].

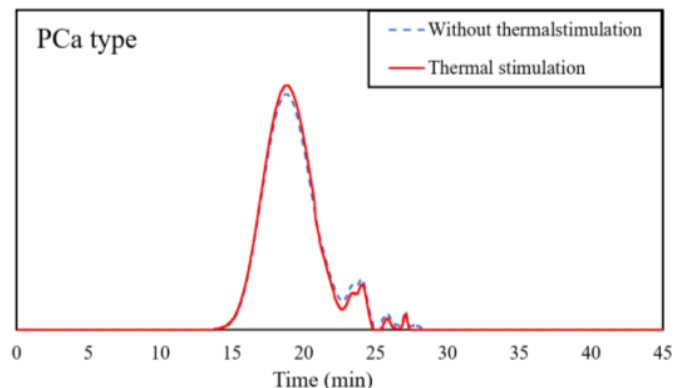

Fig. 5. Influence of thermal stimulation on molecular weight distribution.

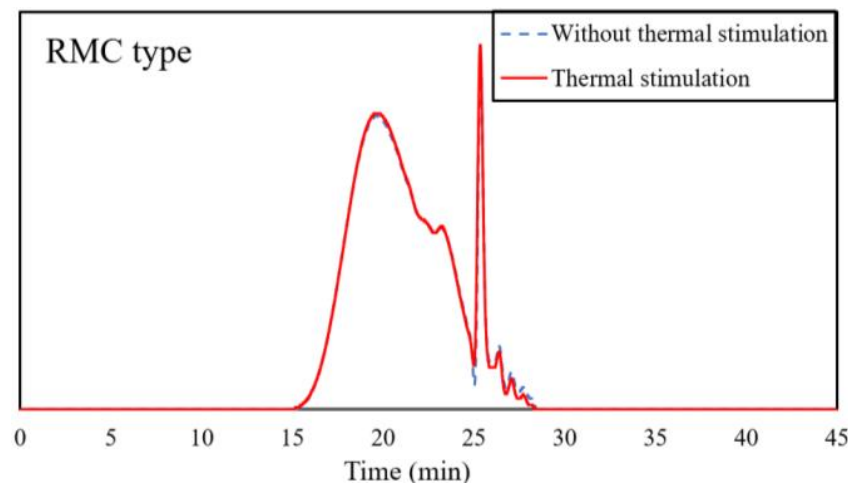

Fig. 6. Influence of thermal stimulation on molecular weight distribution

The dosage of superplasticizer were set so that mortar flow values (without tamping) ranged as $110 \pm 5 \mathrm{~mm}$ and as $120 \pm 5$ mm, respectively, in Case 1 and Case 2. And, in this study, superplasticizers without heating in temperature of $20^{\circ} \mathrm{C}$ were used as control. Temperature of mixing water used was unify 
to $20 \pm 2^{\circ} \mathrm{C}$, and the temperature of the mortar just after mixing were set to be $23 \pm 2{ }^{\circ} \mathrm{C}$ regardless of whether thermal stimulation.

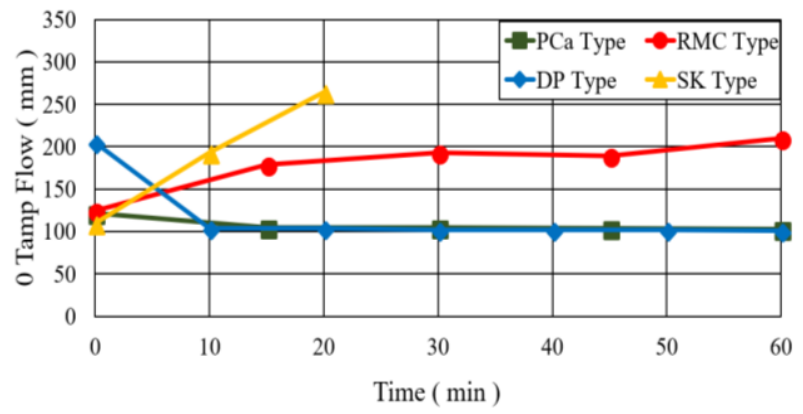

Fig. 7. Slump life of 0 tamp mortar flow (without heating).

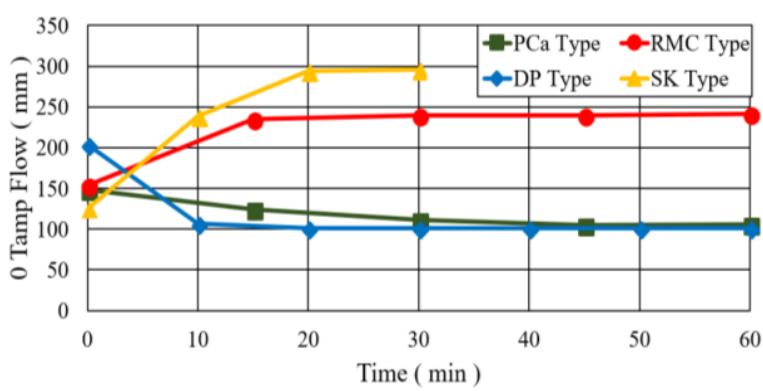

Fig. 8. Slump life of 0 tamp mortar flow (heated $60^{\circ} \mathrm{C}, 24 \mathrm{hr}$ ).

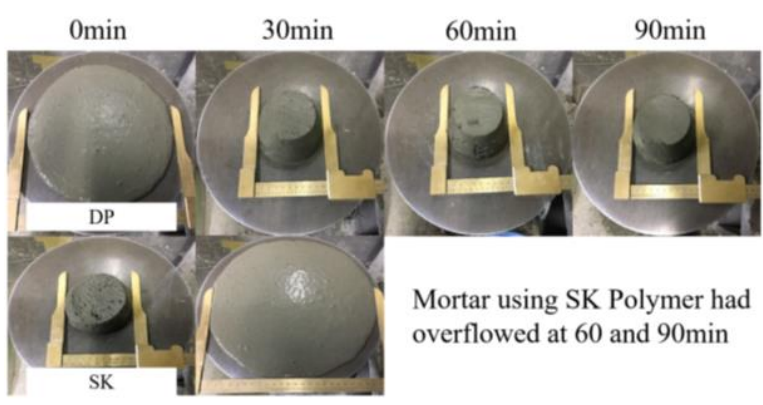

Fig. 9. Appearance of flow change of mortar (without heating).

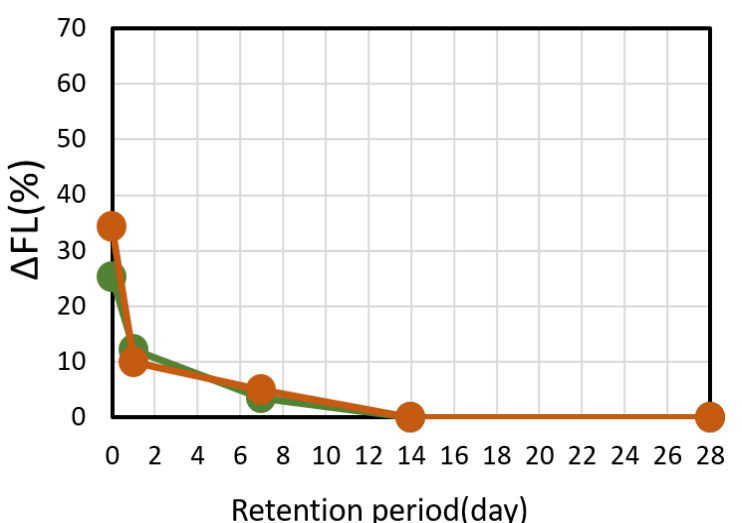

Fig. 11. Relation between heating time and rate of change in fluidity ( $\mathrm{PCa}$ type).

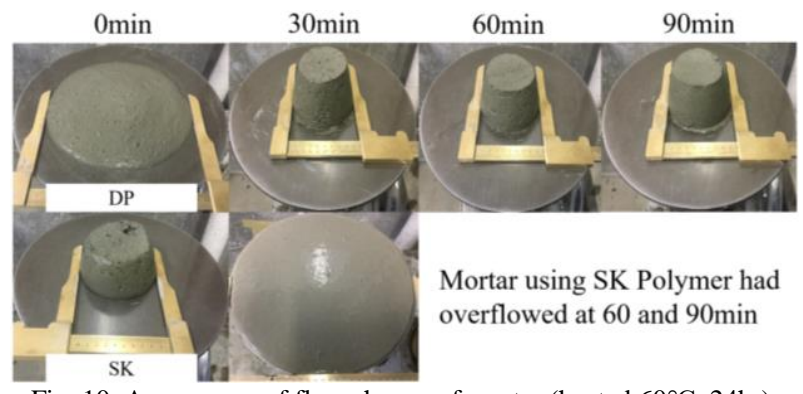

Fig. 10. Appearance of flow change of mortar (heated $60^{\circ} \mathrm{C}, 24 \mathrm{hr}$ ).

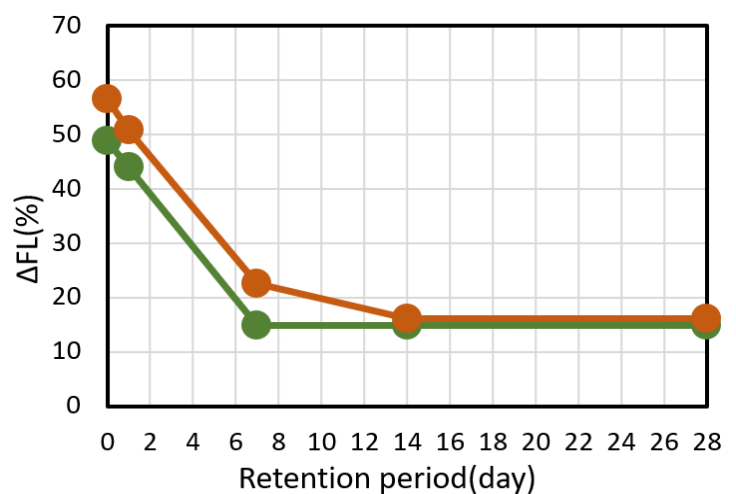

Fig. 12. Relation between heating time and rate of change in fluidity (RMC type)

The slump life of the mortar was evaluated in Case 1, and the sustainability of the thermal stimulation effect was confirmed in Case 2. In each case, heating temperature and heating time of superplasticizers were set on the same conditions.

For DP and SK types, sand cement ratio were set to be 1.0, because dispersion performance of them are significantly different from the others. In order to facilitate confirmation of the residual degree of the thermal stimulation effect when evaluating cooled slowly storage, the dosage of superplasticizers used was increased.

After thermal stimulation, slowly cooling was carried out in a temperature-controlled room at $20^{\circ} \mathrm{C}$. and $60 \% \mathrm{RH}$ until 1 , 7, 14 and 28 days. An influence of type and content of slump keeping polymer on the effect of thermal stimulation were investigated.

All types superplasticizers contain polycarboxylic acid ether-based polymer. PCa and RMC can be produced by blending of both SK and DP, but the mixing ratio of SK type polymer tends to be higher in RMC type than in PCa. Dosage of the superplasticizers were set to be a constant initial mortar flow value (without tamping) for each mix proportions.

\section{Method of Thermal Stimulation}

Each kind of superplasticizer was put in small bottles and was kept in a hot water as the same temperature. Moreover, this one was put in heat chamber, and superplasticizers ware heating to keep warm. Also, all the bottles were shielded to prevent from evaporation of water in the superplasticizer and to maintain solid content.

\section{Method of Experiment}

Mixing procedure is shown in Fig.2. Fresh test of the mortar was conducted in accordance with the JIS R 5201 "Physical testing methods for cement". And also, in Case 2 the effect of thermal stimulation the value of mortar flow compared with presence or absence of thermal stimulation by the index shown in Equation (1) [7]-[10].

$$
\Delta \mathrm{FL}(\%)=(F s-F i) / F i \times 100
$$

$F s$; Mortar Flow after thermal stimulation (mm) $\mathrm{Fi}$; Mortar Flow before thermal stimulation (mm)

In addition, in order to confirm the change in molecular weight distribution in the thermal stimulation effect, the change in the molecular weight distribution of the polymer 
molecule in the superplasticizer was investigated using GPC[19]. In this study, it was diluted with a $0.1 \mathrm{M}$ sodium chloride aqueous solution so that the concentration of the solute to be $1 \%$. Also the flow rate of the sample was set to be $1 \mathrm{ml} / \mathrm{min}$, and the measurement was carried out for 45 minutes.

\section{RESULTS AND DISCUSSION}

The thermal stimulation effect on the change of the molecules geometrically structure of the PCE polymer, an ingredient of the superplasticizer, can be evaluated by the distribution function of relaxation time by DLS. The results confirmed in previous studies are shown in Fig. 3 and Fig. 4 [8]. As shown in the figure, without relation to the kind of superplasticizers, it is found that polymer molecule size increases by applying thermal stimulation.

The effects of thermal stimulation on each superplasticizers on the molecular weight distribution is shown in Fig.5 and Fig. 6. Changes in the molecular weight distribution of polymer molecules were also feared due to thermal stimulation, but in this study, it was confirmed that the effect of thermal stimulation does not affect the molecular weight distribution of polymer molecules. Impact by thermal stimulation to all types Superplasticizers (PCa, RMC, DP, SK type) using ordinary portland cement on slump life of mortar without tamping were shown in Fig. 7 and Fig. 8. Moreover, appearance of flow change of each mortar are shown in Fig. 9. and Fig.10. As the result from the Fig. 7 and Fig. 8, it was confirmed that the fluidity of mortar right after mixing were obviously improved on the case PCa and DP, however, fluidity of mortar 10minutes after mixing were decreased. In addition, RMC type and SK type were more increase slump keeping performance than other 2 types, it was confirmed that the effect of thermal stimulation to these types polymer can be maintained after mixing. Among them, mortar flow test after 40 minutes could not be conducted, because SK type showed much higher effect in compared to DP type. As these results, it was confirmed that the effect of thermal stimulation and its sustainability will be improved as the content of SK type in the superplasticizer increases. In the previous studies [7-10], only fluidity of the mortar right after mixing were investigated, in this study, the effect of thermal stimulation after mixing had been evaluated. Moreover, it was confirmed that even if the initial dispersion performance improves by thermal stimulation, slump keeping performance can be maintained.

The retention of the thermal stimulation effect on each superplasticizer are shown in Fig. 11and Fig. 12. As the results, it was confirmed that the effect of improving fluidity and retention effect by thermal stimulation to the superplasticizers can be last around 7 days. About the types of superplasticizers, in compared to $\mathrm{PCa}$ type, RMC type showed better retention of the effect.

There result concluded to estimate that polymer relax and straighten by thermal stimulation. Moreover, in previous studies [7]-[10], when the more contained amount of slump keeping polymer, it was recognized that the polymer was relaxing for thermal stimulation. However, it is thought that by cooled slowly it will return to the size and geometric structure of stable polymer molecules in the state before thermal stimulation. Therefore, the subject of future investigation, verify the change of the geometric structure itself of the polymer molecule in the effect of the thermal stimulus.

\section{CONCLUSION}

Influence of High range water reducing agent of polycarboxylic acid ether type and high range $\mathrm{AE}$ water reducing agent were heated to verify the effect on molecular weight distribution. Regarding the effect of thermal stimulation to PCE-based superplasticizer, the change of the molecular weight distribution of the raw material polymer was investigated, and the sustainability of the effect after slowly cooling under ambient temperature was evaluated by the fluidity of mortar.

The following findings were obtained within the scope and conditions of this study.

1) It was confirmed that the thermal stimulation doesn't affect to the polymer molecular weight distribution in the superplasticizer and affects only the polymer molecular size.

2) When superplasticizer containes much amount of slump keeping polymers, an effect of thermal stimulation will be getting higher.

3) Even if the initial dispersion performance improves by thermal stimulation, slump keeping performance can be maintained.

4) The improvement of fluidity by the thermal stimulation effect and the sustainability of the effect remained were about 7 days, and it was confirmed that the residual characteristics differed depending on the superplasticizer.

In the future, in consideration of actual use at the construction site, similar tests are being scheduled using different types of cement and superplasticizers for improving the versatility and reliability of this technology. Also, even with the same polycarboxylic acid ether type superplasticizer, because the performance varies depending on the application to be used, the optimization of the treatment condition of the thermal stimulation adapted to the product will be conducted as well.

\section{REFERENCES}

[1] A. Papo and L. Piani, "Effect of various superplasticizers on the reological properties of Portland cement pastes," Cem Concr Res, vol. 34, pp. 2097-2101, 2004.

[2] A. Ohta and T. Uomoto, "Study on dispersion effect of the polycarboxylic acid-based dispersant to fine powder particles," Journal of Concrete Engineering Annual Papers, vol. 10, pp. 79-84,1999.

[3] K. Yamada, T. Takahashi, S. Hanehara, and M. Matsuhisa, "Effects of polyethlene oxide chains on the performance of polycarboxylate-type water-reducers," Cem Concr Res, vol. 35, pp. 867-873, 2005

[4] D. Hamada, T. Sato, F. Yomoto, and T. Mizunuma, "Development of new superplasticizer and its application to self-compacting concrete," in Proc. the 6th CANMET/ACI International Conference on Superplasticizers and Other Superplasticizers in Concrete, pp. 269-290, 2000

[5] K. Yamada, S. Ogawa, and S. Hanehara, "Controlling of the adsorption and dispersing force of polycarboxylate-type superplasticizer by 
sulfate ion concentration in aqueous phase," Cem Concr Res, vol. 31 , pp. 375-383, 2001.

[6] H. Kato, I. Yoshioka, and A. Nakamura, "Influence of temperature on dispersion effect of cement particles by high performance $\mathrm{AE}$ water reducing agent," Journal of Concrete Engineering Annual Papers, vol. 21, no. 2, pp. 163-168, 1999

[7] M. S. Salehi, Z. Tahery, S. Sasaki, and S. Date, "Effect of thermal stimulation of superplasticizer to workability of the mortar," International Journal of Engineering and Technology, vol. 9, no. 3, pp. 138-188, 2017.

[8] M. Takigawa, S. Doi, R. Kita, and S. Date, "Fundamental study of fluidity on mortar appertaining to thermal stimulation of superplasticizer," Japan Society of Civil Engineers, pp. 701-702, 2017.

[9] D. Takehisa, M. Takigawa, R. Kita, and S. Date, "Study on polymer structure of superplasticizer by Dynamic light scattering method," The 2nd MNTC International Symposium, p. 004, 2017.

[10] Z. Tahery, R. Faraidoon, and S. Date, "Effect of delaying addition of heat stimulated superplasticizer on fresh properties of mortar," Materials Science Form, vol. 890, pp. 396-400, 2017.

[11] K. Yamada, T. Takahashi, S. Hanehara, and M. Matsuhisa, "Effects of polyethlene oxide chains on the performance of polycarboxylate-type water-reducers," Cem Concr Res, vol. 35, pp. 867-873, 2005.

[12] R. J. Flatt, J. Zimmermann, C. Hampel, C. Kurz, L. Frunz, C. Plassard, and E. Lesniewska, "The role of adsorption energy in the sulfate-polycarboxylate competition," in Proc. International Conference on Superplasticizers and Other Superplasticizers in Concrete, Seville, vol. 262, pp. 153-164, 2009

[13] Q. Ran, P. Somasundaran, C. Miao, J. Liu, S. Wu, and J. Shen, "Effect of the length of the side chains of comb-like copolymer dispersants on dispersion and rheological properties of concentrated cement suspensions," Journal of Colloid and Interface Science, vol. 336, pp. 624-633, 2009

[14] A. Ohta and T. Uomoto, "Study on dispersion effect of polycarboxylic acid type dispersant on various binding particles," Journal of Concrete Engineering Annual Papers, vol. 20, no. 2, pp. 85-90, 1998.

[15] H. H Bache, "Densified cement ultra-fine particle-based materials," in Proc. the 2th International Conference on Superplasticizer in Concrete, Ottawa, pp. 185-213, 1981.

[16] J. P. Baker, D. R. Stephens, H. W. Blanch, and J. M. Prausnitz, "Swelling equilibria for acryloamide - Based poliampholyte hydrogels," Macromolecules, vol. 23, pp. 1955-1958, 1992.

[17] E. Iiba, M. Kinoshita, J. Inagaki, and T. Nawa, "Influence of chemical structure of polycarboxylic acid type dispersant on fluidity," Journal of Concrete Engineering Annual Papers, vol. 22, no. 2, 2000.

[18] A. Ohta and T. Uomoto, "Fundamental Study on chemical structures of advanced superplasticizers and thier effect on flowavility," Dispersing Effect of Polycarboxylate Dispersant for Sparticle Size Controlled Cement, Jounal of seiSAN-Kenkyu, vol. 50, pp. 422-425, 1981.

[19] A. Ohta and T. Uomoto, "Fundamental study on the chemical structures of advanced superplasticizers and thier effect on flowavility of mortar," Jounal of Seisan-kenkyu, vol. 49, pp. 637-640, 1997.

[20] T. Nawa and H. Ichiboji, "Influence of temperature on the fluidity of high range AE water reducing agent adding cement paste," Journal of Concrete Engineering Annual Papers, vol. 20, no. 2, pp. 79-84, 1998

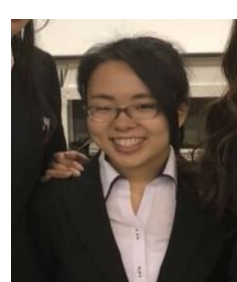

Mizuki Takigawa was born in Kanagawa prefecture on November 17, 1995. She graduated with the bachelor's degree of civil engineering course in Tokai University, Hiratsuka city, Kanagawa, Japan in Mar 2018. Now she is a candidate of master of civil engineering course of Tokai University. Her research interests are about engineering of fresh concrete and precast concrete. She is a member of JCI and JSCE.

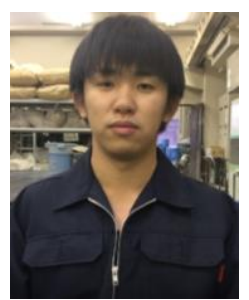

Yu Bomura was born in Kanagawa prefecture on May 25, 1995. He graduated bachelor's degree of civil engineering course in Tokai University, Hiratsuka city, Kanagawa, Japan in Mar 2018. Now he is a candidate of master of civil engineering course of Tokai University. He researches interests are about engineering of fresh concrete and precast concrete. $\mathrm{He}$ is a member of JSCE.

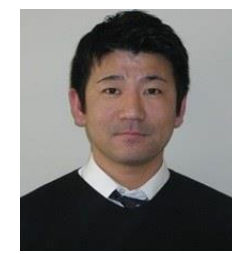

JSCE, AIJ.

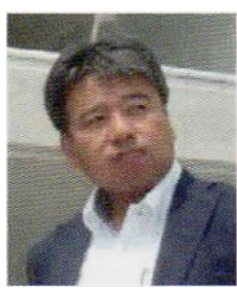

Shigeyuki Date was born in Fukuoka, Japan. He graduated from Nagasaki University in 1987; the doctor of engineering, Gunma University in 2005 , Gunma Japan. His major field of study are concrete engineering, maintenance engineering. He is working for Tokai Univ. as professor of Dept. of Civil Engineering. Current and previous research interests are material design, durability of concrete structure, concrete production, and precast concrete. Dr. Date is member of JCI, JSCE, AIJ, SMSJ. 